\title{
Do impersonal mobilisation methods work? Evidence from a nationwide Get-Out-the-Vote experiment in England
}

\author{
Edward Fieldhouse ${ }^{\mathrm{a}, *}$, David Cutts $^{\mathrm{b}}$, Paul Widdop $^{\mathrm{a}}$, Peter John ${ }^{\mathrm{c}}$ \\ ${ }^{a}$ Institute for Social Change, University of Manchester, Oxford Road, Manchester M13 9PL, UK \\ ${ }^{\mathrm{b}}$ Department of Politics, Languages and International Relations, University of Bath, UK \\ ' School of Public Policy, University College London, UK
}

\section{A R T I C L E I N F O}

\section{Article history:}

Received 20 March 2012

Received in revised form 12 July 2012

Accepted 17 September 2012

\section{Keywords:}

GOTV

Field experiment

Synergy

Impersonal mobilisation

Turnout

\begin{abstract}
A B S T R A C T
While face-to-face mobilisation has a demonstrable effect on voter turnout, a series of field experiments show that impersonal methods, such as telephoning and direct mail, are less effective. This paper provides a new test of the effectiveness of telephone and direct mail on voter turnout, which uses a large nationally representative Get-Out-the-Vote two-wave field experiment. We find that impersonal methods are more effective, though the magnitude depends on electoral context. Moreover, these effects accumulate both within and across elections as voters are exposed to multiple contacts. However this is an incremental and cumulative process, not the product of synergy.
\end{abstract}

(c) 2012 Elsevier Ltd. All rights reserved.

\section{Introduction}

One influential line of work claims that the decline in political participation since the 1960s has been influenced by the dramatic transformation in the way voters are mobilised (Rosenstone and Hansen, 1993; Gerber and Green, 2000a). The modern era of professionalism has seen the promotion of mass marketing techniques and modern campaign methods at the expense of personal mobilisation. Political parties have become more professional at the national level, managing and targeting effort and resources in key battleground constituencies and, recently, on key individual voters using less personal methods, such as direct mail and centrally organised telephone banks. With declining party membership in most western democracies, and generally fewer activists, partisan organisations are becoming more reliant on impersonal techniques and less on face-to-face contacts (Fisher and Denver, 2008).

Gerber and Green (2000a) claim the decline of personal mobilisation has contributed to the erosion of voter turnout

\footnotetext{
* Corresponding author.

E-mail address: ed.fieldhouse@manchester.ac.uk (E. Fieldhouse).
}

in the United States since the 1960s. By conducting numerous randomised control trials, Gerber, Green and colleagues (Gerber and Green, 2000a,b; 2001; Gerber et al., 2003; Green et al., 2003; Green, 2004; Green and Gerber, 2004) show that face-to-face mobilisation has a strong effect on voter turnout and is far more effective than less personal methods, such as telephoning and direct mail (see also McNulty, 2005). Other studies suggest there is no hierarchy of effects according to the extent of personal mobilisation. For example, Nickerson (2006) finds an effect for telephoning, and, in an experiment in a single parliamentary constituency in the United Kingdom, John and Brannan (2008) show a treatment effect of 7.3 per cent for the telephoned group and 6.7 for those canvassed door-todoor. So does this mean there is potential for more impersonal techniques after all? This study examines whether telephone and direct mail, either alone or in combination, have the potential to increase turnout in a nationally representative sample of constituencies in England. The impact of non-partisan mobilisation is evaluated through three GOTV interventions - telephone canvassing, direct mail, and a combination of both mail and telephone - on voter turnout in two successive elections in England. 
There are two important features of this study which make it unique in the literature on voter turnout field experiments. First, we compare different modes singularly and in combination over two successive elections. Whereas prior studies evaluated the effectiveness of different modes of contact in one intervention, double treatments and those done in successive elections provide a more accurate representation how political agencies use impersonal techniques to influence voters. Unlike a one-off contact with electors, a succession of impersonal contacts might enable the agency to build a relationship with the elector, creating a more effective intervention through synergy. We aim to create an intervention that resembles those carried out by third party organisations, providing an improved test of impersonal methods. Although extrapolation to partisan mobilisation efforts must be made with caution, non-partisan campaigns similar to ours are increasingly common (for example those carried out by the UK Electoral Commission in recent General Elections). In such interventions, citizens might expect to get several contacts from one or more organisations in different forms whereby (for example) a letter might be followed by a telephone call. We test whether re-contacting the same electors on multiple occasions through multiple media can enhance the impact of a message through re-enforcement; or indeed whether multiple communications might lessen the chance of a message being successful as respondent's tire of being targeted. Second, the study is based on a nationally representative probability based sample that affords an unusually high standard of external validity (Mutz, 2011). In particular we are able to ensure the size of treatment effects is not an artefact of choosing a particular geographical study area as in almost all previous studies and even recent meta-analyses based on a relatively small number of treatments (Green et al., 2010).

\section{Synergy and accumulation? The effectiveness of combined and repeated impersonal treatments}

Classic GOTV studies (Gerber and Green, 2000a) make inferences about impersonal and personal methods by comparing the treatment effects of canvassing, telephoning and other interventions in a series of one-off experiments (Arceneaux, 2005; Bennion, 2005; Gerber and Green, 2000a, 2000b; 2001, 2005; Gerber et al., 2003; Green, 2004; Green et al., 2003; Green and Gerber, 2004; Green and Shachar, 2005; McNulty, 2005; Nickerson, 2007a; Trivedi, 2005; Wong, 2005). As noted above a substantial body of previous evidence suggests that impersonal methods of non-partisan mobilisation are less effective than door-to-door canvassing (Green and Gerber, 2004; McNulty, 2005). Notwithstanding this, some studies show that when telephone interventions are relatively personal (e.g. through volunteer phone banks) telephone mobilisation can be effective (Nickerson, 2006, 2007b). The implication of these studies is that more impersonal campaigns rely on complementary forms of contact, perhaps to show that the organisation that intervenes is really interested in the respondent. There is some evidence of the effects of this practice in another UK study (John and Brannan, 2008), where the researchers mailed respondents in advance of treatment with information about the campaign. Survey researchers have also shown that sending a letter in advance of a telephone survey increases response rates (Goldstein and Jennings, 2002).

In spite of the use of double techniques by campaigners and survey companies, most of these studies adopt single modes of contacting potential voters. As the marketing industry and increasingly, political campaigners are aware, the notion of reinforcement may be crucial. Whilst there is some evidence that repeated interventions (e.g. multiple mail shots, Gerber and Green, 2000a; Green et al., 2010) can be more effective than single treatments, there is less evidence about mixed or combinations of treatments. It is reasonable to suppose that the culmination of interventions may lead to enhanced treatment effects as recipients become more familiar with external party and more likely to recollect the campaign. This is the phenomenon of synergy whereby the impact of the campaign is greater than the sum of its constituent parts.

The only previous studies that have explored the effectiveness of telephone and mail campaigns in combination have covered subgroups of electors or geographic areas in the U.S. Green (2004) conducted an experiment based on the mobilization of African American electors (NAACP) using a combination of mail and telephone interventions. Both treatments effects were relatively small, and the combined effect of mail and telephone produced a weak effect. Cardy (2005) looked explicitly at the effect of telephone in conjunction with mail, but found no effect, although the sample size was small. Ramirez's (2005) analysis of the NALEO study of Latino voter mobilisation found that the combined effect of mail and telephone was no greater than the separate (additive) sum of separate mail and telephone treatments. Reflecting on the 1998 New Haven study, and on the NAACP and NALEO studies cited above, Green concluded that 'special combinations of GOTV appeals do not appear to deliver a bonus' (Green and Gerber, 2004, p. 97).

\section{Data and methods}

We examine the effect of non-partisan mobilisation, through telephone canvassing and direct mail, on voter turnout in the European elections in England on June 4th 2009 and the U.K. General Election on May 6th 2010. Using a multistage sample design with stratification and clustering, we randomly sampled twenty-seven local authority districts, and then three electoral wards from each district. Using a commercial database, based on electoral registers and telephone records, 40,000 individuals were sampled from these eighty-one wards. The sample was further stratified by household and restricted to one random person per household to avoid clustering, and to ensure some households did not receive double treatments. In other words, 40,000 households were selected and one person was taken at random from each. This sample was further stratified according to telephone accessibility and therefore included two separate sub-samples:

1. Telephone accessible (any record with a valid landline or mobile): 26,500 individuals 


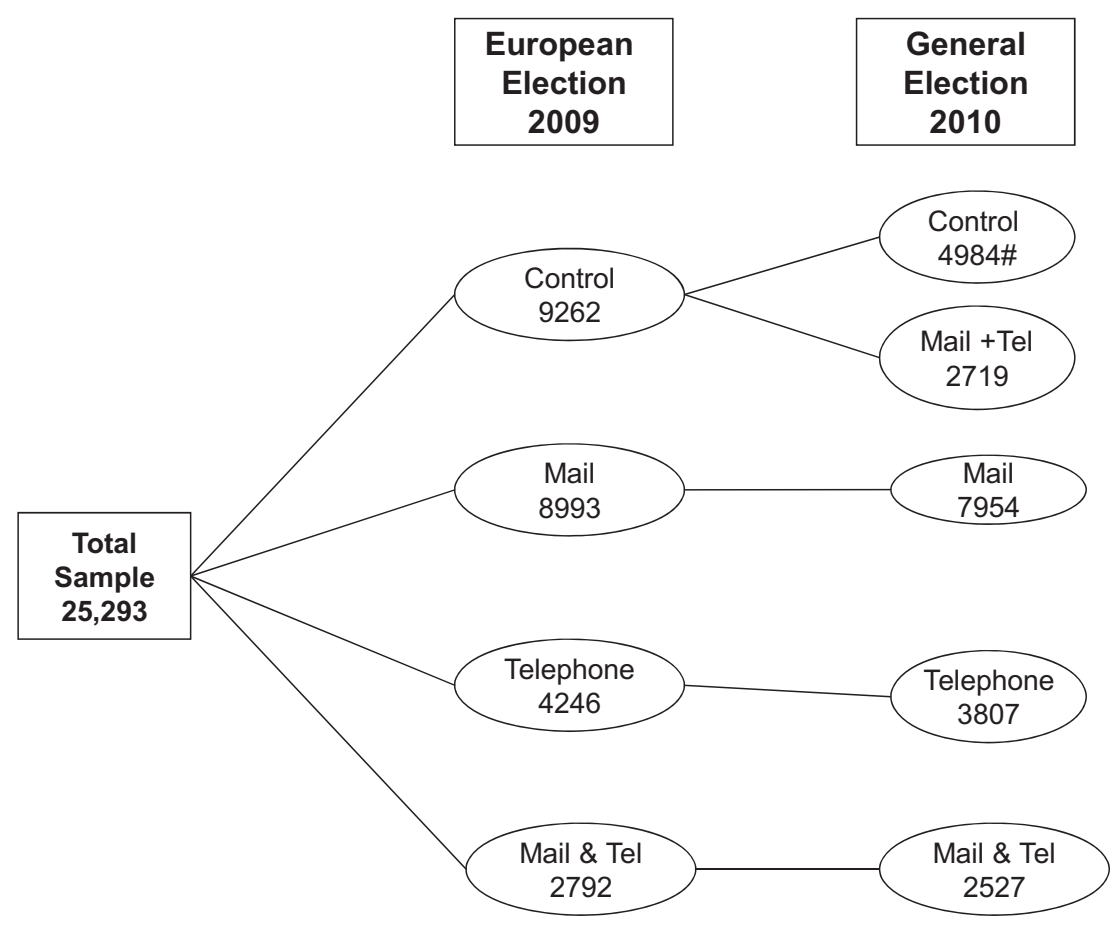

\# 610 unknowns removed randomly from control to balance telephone accessible and inaccessible in correct proportions

Fig. 1. Study design (with sample size - all registered eligible electors including postal voters).

2. Telephone inaccessible (anyone with no telephone contact information): 13,500 individuals

In total 981 telephone accessible and 500 telephone inaccessible individuals were sampled in each local authority district, spread across three sampled wards in the district. Each individual was randomly assigned to one of three treatment groups (telephone, mail or mail and telephone). Fig. 1 depicts our design. After the randomisation was complete, ${ }^{1}$ any electors in the sample (treatment or control groups) that were not registered or not eligible to vote were removed, leaving a sample of 25,293 in 2009. This reduction reflects redundancy in the sampling frame particularly arising from non-registration (since we include only registered electors in the analysis). At the General Election of 2010, we canvassed the sample again, but with the difference that we randomly allocated a portion of the 2009 control group to a new mail and telephone treatment group. Members of the three 2009 treatment groups were assigned to receive a repeat dose of the same treatment in 2010. A proportion of the sample that was included in 2009 had left the electoral register in 2010 or had changed name/ address details and was therefore excluded, leaving a sample of 21,984 in 2010 (the second stage in Fig. 1). ${ }^{2}$

\footnotetext{
${ }^{1}$ Balance tests confirmed that there were no significant differences between the control and treatment groups in respect to individual and ward characteristics (tables available on request).

${ }^{2}$ In 2010, 610 telephone inaccessible electors were randomly removed for the control group to ensure that the ratio of accessible to inaccessible electors remained the same as in the mail treatment group. Votes were not recorded for these electors so are missing in 2010 analysis.
}

By sampling the mail and control group from both telephone accessible and inaccessible numbers we are able to observe whether there is any difference in the propensity to vote and in the effectiveness of a (mail) treatment between those with and without telephone information. This informs the interpretation of the telephone treatment effect, which is restricted to the telephone accessible sample.

\subsection{The intervention}

The study was designed around a specially created GOTV campaign called 'Your Vote' which encouraged recipients of the treatment to vote for reasons of civic duty and also to 'have their say'. Telephone recipients received a short phone call from a trained team of social science graduate students. Calls were approximately two minutes in length. All non-respondents were called back on five occasions at different times of the day to maximise the overall contact rate. The mail group received a personalised printed letter in a colour with almost identical message (tailored for the written word). This is reproduced below (Fig. 2). It is important to note that, as in most real world campaigns, the intervention was not completely impersonal as subjects were addressed by name (Nickerson, 2006).

The impact of the treatment was assessed by recourse to the official records of voter turnout after the election. These are the electoral registers kept by local authorities that are marked-up at the polling station to record when electors' votes have been cast. All sampled electors, including treated, non-contacts and control, were checked against 


\section{INSERT FIRSTNAME AND SURNAME \\ INSERT ADDRESS FIELD1 \\ INSERT ADDRESS FIELD2 \\ INSERT ADDRESS FIELD3 \\ INSERT TOWN \\ INSERT POSTCODE}

$23^{\text {rd }}$ May 2009

\section{Dear INSERT FIRSTNAME}

\section{Remember to cast 'your VOTE' on Thursday $4^{\text {th }}$ June}

Election time is here again. Show your support for the community by voting on polling day $4^{\text {th }}$ June 2009 . Make yourself heard; your vote really does count!

A democratic system like we have in Britain is a privilege, and we often forget that we are fortunate enough to live in a country that allows us the freedom to cast our vote in any manner we see fit, which is not the case in many other countries. Many people from previous generations fought for the right to vote.

If there is time, send off your postal vote. Or go to your nearest polling station on Thursday $4^{\text {th }}$ and have your say!

Yours

Campaign Coordinator

For more information about how to vote, have a look at your polling card. Or call your local elections office at your local council or click on http://www.aboutmyvote.co.uk/

'your VOTE ' is an independent GOTV research team organised by the Institute of Social Change. For further details contact us at socialchange@manchester.ac.uk or on 01612754269

Fig. 2. Treatment letter.

the registers lodged with the appropriate local authorities. This design has the important advantage that it allowed us check for any bias in contact levels (compliance versus noncompliance) and non-registration within the treatment and control groups (see Table 1 ). The total number of registered electors in the sample was 25,293 in 2009 and 21,984 in 2010 . Of those in the telephone treatment group, $58 \%$ were successfully contacted in 2009 and $78 \%$ in $2010 .^{3}$ This is a relatively high success rate and reflects the large number of attempts to call back at different times of the day.

In $2009,17 \%$ of electors in our initial sample voted by post, and $20 \%$ did so in $2010 .{ }^{4}$ As a result of electoral law, there is no public record that indicates whether, individually, these people cast their vote, though in 2010 , across England, over $80 \%$ of all allocated postal votes were received and validated. Because of the timing of the

\footnotetext{
${ }^{3}$ Contact is defined as having successfully delivered the script to the target elector. There were a number of reasons for non-contact with the majority being refusal (60\% of non-contacts) followed by no-answer after 5 call backs (21\%) and incorrect number/details (15\%).
}

\footnotetext{
${ }^{4}$ According to official figures from the Electoral Commission across England as a whole approximately $16 \%$ of electors were allocated postal votes and $19 \%$ of all votes were cast by post in 2010. Figures are not available for 2009 .
} 
Table 1

Sample size and contact rates by treatment group.

\begin{tabular}{lccll}
\hline & $\begin{array}{l}\text { Sampled } \\
\text { registered } \\
\text { electors }^{\mathrm{a}}\end{array}$ & $\begin{array}{l}\text { Of which } \\
\text { telephone } \\
\text { accessible }\end{array}$ & $\begin{array}{l}\text { Contacts } \\
\text { achieved by } \\
\text { telephone }\end{array}$ & $\begin{array}{l}\text { Contact } \\
\text { rate }^{\mathrm{b}}\end{array}$ \\
\hline $\mathbf{2 0 0 9}$ & 9262 & 6361 & - & - \\
Control & 4246 & 4246 & 2435 & $57.3 \%$ \\
$\begin{array}{l}\text { Telephone } \\
\text { Mail }\end{array}$ & 8993 & 5300 & - & - \\
Mail + tel. & 2792 & 2792 & 1640 & $58.7 \%$ \\
Total $\boldsymbol{N}$ & 25,293 & 18,699 & & \\
$\mathbf{2 0 1 0}$ & & & & - \\
Control & 4984 & 2994 & - & - \\
Telephone & 3807 & 3807 & 2989 & $79.9 \%$ \\
Mail & 7954 & 4784 & - & $79.4 \%$ \\
Combined & 2719 & 2719 & 2174 & \\
Double treatment & 2527 & 2527 & 2006 & \\
$\quad$ combined & & & & \\
Total $\boldsymbol{N}$ & 21,984 & & & \\
\hline
\end{tabular}

a This excludes redundant individuals in sample (contacts not registered to vote). Those not registered to vote in 2009 were not included in the 2010 sample.

b Contact rate for mail is unknown. Contact rate for combined group refers to telephone contact.

intervention (within eleven days of each election) ${ }^{5}$ the treatment could only encourage postal voters to cast their ballot, not to apply for a postal vote. Therefore we treat postal voters as missing data excluding them from the subsequent analysis.

\section{Results}

The rates of voting and non-voting by treatment group are shown in Table 2. First, the levels of turnout in the control group broadly match the official turnout in England for the respective elections. It is also clear that electors who are telephone accessible are more likely to vote than the sample as a whole. It is therefore important to separate the effect of telephone accessibility from the treatment effects by disaggregating the estimates accordingly.

Briefly, we see that amongst the telephone accessible in 2009 and 2010, the telephone treatment group (40.3\%, $72.2 \%$ respectively) was slightly more likely to vote than the control group (39.7\%, 68.8\%). The corresponding rate for telephone accessible mail recipients was $41.3 \%$ and $70.6 \%$, and for those who received both treatments $(41.8 \%$ and $72.8 \%$ ). The latter refers to those receiving both mail and telephone for the first time in 2010. Those receiving a repeat mail and telephone combination had a slightly lower turnout rate of turnout (71.8\%). This gives some indicative evidence that both treatments increased turnout and some support for the synergy hypothesis, but in order to rule out random variation we must test the statistical significance of the intention to treat (ITT) effects. For mail recipients we can extend the sample to include those who are not telephone accessible. In this group the turnout rate in 2009 was $33.7 \%$ compared to $32.7 \%$ in the equivalent treatment group.

\footnotetext{
${ }^{5}$ The deadline for receipt of postal vote application is eleven days before an election.
}

\subsection{Estimating the treatment effect}

If, after randomly assigning individuals to control and treatment groups and conducting the interventions, everyone in the treatment group were actually contacted then this would be the actual treatment effect. However, in practice, it is not possible to make such simple inferences about the impact of the telephone intervention because some citizens assigned to the telephone treatment group and the combined treatment group could not be reached (see Table 1). To overcome this difficulty, it is necessary to distinguish between the intent-to treat (ITT) effect and the effects of actual contact (Gerber and Green, 2000a, 2001, 2003). The intent-to-treat effect is simply the observed difference in voter turnout between those assigned to the treatment and control groups.

Consider the following model:

$Y=a+\operatorname{tr} X+u$

$Y$ is specified as a dichotomous variable $(0,1)$ indicating whether an individual votes or not, and $X$ is whether an individual was contacted by telephone during the experiment. The coefficient $\mathrm{tr}$ is the treatment effect, the increase in voting caused by contact with the telephone canvassers from the GOTV experiment.

Contact is a function of whether an individual was assigned to the treatment or control group of the experiment. In Equation (2) we therefore specify variable $Z$ (also as dichotomous) to indicate being randomly assigned to one of these experimental groups. It can be expressed as follows:

$X=c r Z+e$

To estimate the actual treatment effect (tr) given a contact rate (cr), we must obtain the intent-to-treat effect (itt) and divide it by the contact rate (cr) (Gerber and Green, 2000a: p. 657):

$i t t / c r \Rightarrow t r$

This is comparable to running a two-stage least squares regression of vote on actual contact with randomisation as the instrumental variable (Gerber and Green, 2000a; Angrist et al., 1996). In the case of the mail and combination treatment effect, we cannot know how many of the mail shots were received or read by the intended recipients, and it is therefore necessary to treat all intended recipients as having been contacted. ${ }^{6}$ This is a conservative assumption

\footnotetext{
${ }^{6}$ We estimate the mail treatment effects in 2009 and 2010 and the control in the same elections as follows:

$V_{M}=\gamma\left(V_{R}+\beta\right)+(1-\gamma) V \sim_{R}$

$V_{C}=\gamma V_{R}+(1-\gamma) V \sim_{R}$

where $V_{R}$ is the baseline voting rate for those individuals who can be reached by the campaign and $V \sim_{R}$ is the baseline voting rate for people who cannot be reached by the campaign. $\gamma$ is the percentage of those who can be contacted by mail (here assumed to be $100 \%$ ). An estimate of the intent-to-treat-effect is simply obtained by subtracting the voter turnout rate of the mail treatment group, $V_{M}$, from that of the control group, $V_{C}$.
} 
Table 2

Turnout rates by intention to treat

\begin{tabular}{|c|c|c|c|c|c|c|c|}
\hline \multirow[t]{2}{*}{$\%$ Voted (n) } & \multicolumn{5}{|c|}{ Telephone accessible electors } & \multicolumn{2}{|c|}{ Telephone inaccesible } \\
\hline & Telephone & Mail & Mail \& tel. & Control & Repeat mail and tel. & Mail & Control \\
\hline In person ${ }^{\mathrm{a}} 2009$ & $40.3 \%(3466)$ & $41.3 \%(4367)$ & $41.8 \%(2287)$ & $39.7 \%(5179)$ & NA & $33.7 \%(3122)$ & $32.7 \%(2467)$ \\
\hline Post/person ${ }^{\mathrm{b}} 2009$ & $51.1 \%(4246)$ & $51.7 \%(5300)$ & $52.4 \%(2792)$ & $50.9 \%(6361)$ & NA & $43.9 \%(3693)$ & $42.7 \%(2901)$ \\
\hline In person ${ }^{\mathrm{a}} 2010$ & $72.2 \%(2993)$ & $70.6 \%(3789)$ & $72.8 \%(2120)$ & $68.8 \%(2352)$ & $71.8 \%(1996)$ & $66.6 \%(2577)$ & $64.6 \%(1644)$ \\
\hline Post/person ${ }^{\mathrm{b}} 2010$ & $78.2 \%(2976)$ & $76.7 \%(3670)$ & $78.9 \%(2719)$ & $75.5 \%(2994)$ & $77.8 \%(2527)$ & $72.8 \%(3170)$ & $70.8 \%(1990)$ \\
\hline
\end{tabular}

a Excludes postal voters from sample.

b Treats all applying for postal vote as having voted. There is no record of whether the postal vote was actually cast, though over $80 \%$ of all postal votes across the country were cast in 2009 and 2010.

that provides the lower bound of the estimate of the treatment effect (equal to the ITT).

Table 3 shows the estimated treatment effect for each part of the experiment for both 2009 and 2010 with postal voters excluded (using Equation (1)). Looking first at the 2009 mail experiment for the telephone accessible group, we see that although the mail recipients were more likely to vote than the control group, the difference (the estimated intent-to-treat effect) was 1.6 percentage points and (very narrowly) statistically insignificant at $p=0.05 .^{7}$ There is a similar effect in 2010 of 1.72 for the telephone accessible sample, which is also narrowly insignificant at $p=0.05$. Amongst the telephone inaccessible group the treatment effect is $1.0 \%$ in 2009 and statistically insignificant. In 2010 the impact of the intervention had doubled amongst this group to 2.0, but it was also narrowly insignificant at $p=0.05$.

Overall, the estimates for direct mail are consistent with previous research (e.g. see Green and Gerber, 2004) and suggest that around one in fifty electors were persuaded by mail at the General Election in 2010 compared to about one in a hundred in the European Elections in 2009. Although these marginally fail to meet conventional levels of statistical significance, the results indicate that there may have been a small positive effect of the mail intervention, which may be detectable when measured across the entire sample (i.e. the single and double treatment groups, telephone accessible and inaccessible). This is explored further below.

The fourth column in Table 3 shows the equivalent statistics for the telephone experiment. Again, in 2009, although the telephone treatment group were more likely to vote than the telephone accessible control group, the ITT (0.6) was not statistically significant. Campaigners are often more interested in the treatment effect on the treated rather on those intended to treat, and in this case the treatment effect allowing for non-contact was 1.0 (and statistically insignificant). However, in 2010 the ITT effect was considerably larger (3.4) and significant as was the treatment effect allowing for contact (4.3). This implies that the telephone campaign had little or no effect in 2009 but in 2010 mobilised as many as one in twenty-three electors who were contacted. There are two main potential sources of difference in the effects between elections. First, there are differences in the context of the two elections. The 2010 election was a first-order election which was closely fought and enjoyed a moderately high level of turnout overall (65\% nationally). By contrast, the 2009 European elections were second order elections which were dominated by an MP's expenses scandal and high levels of alienation and distrust in politicians. The overall turnout nationwide was only $34 \%$. The second possible source of difference is that, whilst in 2009 the treatment groups had not been treated previously, the 2010 mail and telephone interventions were follow-up treatments. Consequently, part of the 2009 effect may have been carried over, either through the development of a voting habit, or through memory of the treatment (Green and Shachar, 2000; Cutts et al., 2009). We cannot, however, fully separate the effects of electoral context from the effect of repeated intervention for the mail and telephone groups. This is discussed further below.

The third experiment examined the impact of receiving both mail and telephone interventions. As described above some 2792 electors were randomly allocated to be contacted by both telephone and mail in 2009. ${ }^{8}$ These had the highest rate of voting in Table 2 (41.8\%). Because we cannot be sure whether everyone allocated to this group received the mail shot, we focus on the ITT which was $2.1 \%$ and statistically significant. The same electors were again treated with both telephone and mail in 2010 and the size of the treatment effect was 3.0\%, and again statistically significant. In addition a fresh sample was treated by mail and telephone, with a slightly larger (significant) treatment effect of $4.0 \%$. This suggests that the combined treatment amongst new subjects was larger in the 2010 General Election than it had been in the 2009 European Election, but that there was no additional boost derived from repeating (following up) the combined intervention. With respect to the potential explanations of enhanced effects in 2010 described above, this implies that electoral context is more important in understanding the larger effect size than the fact that treatments are repeated. Indeed, in this case the lower effectiveness of the repeated treatments suggests the respondents may have experienced too much exposure or fatigue. More generally we can conclude that whilst mail and telephone alone had rather mixed effects, a combined approach, contacting electors by both telephone and mail, was effective at both elections.

\footnotetext{
${ }^{7}$ All tests based on one-tailed test of significance as effects are hypothesised to be positive. The $p$ value of this test is 0.056 . All treatment effects and ITTs are percentage point increase in turnout.
} 
Table 3

Estimated treatment effects.

\begin{tabular}{|c|c|c|c|c|c|}
\hline & $\begin{array}{l}\text { Mail (tel. } \\
\text { inaccessible }\end{array}$ & $\begin{array}{l}\text { Mail (tel. } \\
\text { accessible) }\end{array}$ & Telephone & Combined & $\begin{array}{l}\text { Repeat } \\
\text { combined }\end{array}$ \\
\hline \multicolumn{6}{|l|}{2009} \\
\hline$N$ treatment & 3122 & 4367 & 3466 & 2287 & - \\
\hline$N$ Control & 2467 & 5179 & 5179 & 5179 & - \\
\hline Voted (treatment) & 1052 & 1805 & 1398 & 957 & - \\
\hline Voted (control) & 806 & 2058 & 2058 & 2058 & - \\
\hline $\begin{array}{l}\text { Estimated intent-to-treat } \\
\text { effect (standard error) }\end{array}$ & $1.03(1.27)$ & $1.60 *(1.01)$ & $0.60(1.08)$ & $2.11^{* *}(1.23)$ & - \\
\hline $\begin{array}{l}\text { Estimated treatment } \\
\text { effect (standard error) }\end{array}$ & - & - & $1.07(1.86)$ & - & - \\
\hline \multicolumn{6}{|l|}{2010} \\
\hline N Treatment & 2577 & 3789 & 2993 & 2120 & 1996 \\
\hline N Control & 1644 & 2352 & 2352 & 2352 & 2352 \\
\hline Voted (treatment) & 1716 & 2675 & 2162 & 1545 & 1435 \\
\hline Voted (control) & 1062 & 1620 & 1620 & 1620 & 1620 \\
\hline $\begin{array}{l}\text { Estimated intent-to-treat } \\
\text { effect (standard error) }\end{array}$ & $1.99 *(1.50)$ & $1.72 *(1.20)$ & $3.36^{* *}(1.25)$ & $4.00^{* *}(1.36)$ & $3.01^{* *}(1.38)$ \\
\hline $\begin{array}{l}\text { Estimated treatment } \\
\text { effect (standard error) }\end{array}$ & - & - & $4.32^{* *}(1.62)$ & - & - \\
\hline
\end{tabular}

* Significant at $0.10 ;{ }^{* *}$ significant at 0.05 (one-tailed test). Registered electors only. Assumes all those receiving mail are treated. Postal voters are excluded. $2009 N=20,888,2010 N=17,471$.

However we cannot infer from this that there is any synergy between the two modes of intervention. Clearly there is an additive effect: the combined treatment is significant at $p=0.05$ in both elections whereas the single treatments were not. Moreover, those receiving both treatments are the most likely to vote at both elections. However, in 2009 the combined treatment effect (2.11\%) is slightly smaller than the sum of the single ITT effects $(1.60+0.60=2.20)$. We can calculate the standard error around this difference to be 1.66 giving a $t$-test statistic of 0.55 which is statistically insignificant for a one tailed test at $p=0.05 .^{9}$ Similarly, in 2010, the combined effects for the new treatment group (4.00) and for the repeat treatment group (3.01) are both less than the sum of the two separate treatments $(3.36+1.72 .=5.08)$. The difference between the estimate for the new treatment group (4.00) and the additive effect (5.08) is -1.08 , with a standard error of 1.75 , which is statistically insignificant. For the repeated treatment group the difference is $-2.07 \%$ with a standard error of 2.22 , which is also statistically insignificant.

In other words, although the combined effect of telephone and mail is significant, we cannot reject the null hypothesis that this is a simple additive effect rather than the effect of synergy. By this we mean a second campaign intervention increases turnout by the same amount as the first. Nevertheless, it is both interesting and important that the effects of mail and telephone should accumulate in this way, and provides support for the strategy of making multiple contacts with electors. Although the combined effects are slightly smaller than the sum of the separate treatment effects, there is no firm evidence of diminishing marginal returns. This is explored further in the multivariate models below.

\footnotetext{
9 The relevant proportions and sample sizes for calculating the standard error for the comparison are: combination ( $p=0.42, n=2287)$; tel $(p=0.4, n=3466) ;$ mail $(p=0.41, n=4367)$; $\operatorname{control}(p=0.40, n=5179)$.
}

\subsection{Modelling treatment effects}

The preceding analysis provides an estimate for the effect of each of the treatments separately. The multivariate models below provide a more comprehensive assessment of all the different treatment effects simultaneously and across treatment groups (e.g. effect of mail across both the mail and combination treatment groups). These models also have the additional benefit of allowing us to introduce covariates which may help us explain unobserved variance in the propensity to vote, thus improving the precision of the estimates of treatment effects. In particular we are able to control for the effect of being telephone accessible in our estimation of all the treatment effects since we have selection of telephone accessible and inaccessible within the control and mail treatment groups. In Table 4 we provide an estimate of the treatment effect whilst allowing for telephone non-contact ${ }^{10}$. The model employed is a cross-sectional two-stage instrumental variable probit models for 2009 and 2010 taking into account the effect of contact at both elections, whilst allowing for the effect of voting in 2009 on voting in 2010 (Green and Shachar, 2000; Cutts et al., 2009).

Table 4 shows estimates of the effect of telephone and mail contact across the entire sample, differentiating by telephone accessibility. The models include mail treatment and telephone contact, where telephone contact is the endogenous predictor in the two-stage model and

\footnotetext{
10 If we consider the following model where we take account of an endogenous binary variable.

$Y_{i}=G\left(X_{i}, v_{i}, W_{i}, \varepsilon_{i}\right)$

where $Y_{\mathrm{i}}$ is vote, $X_{\mathrm{i}}$ is an observed binary variable, $v_{\mathrm{i}}$ is a scalar error term, $W_{\mathrm{i}}$ is a vector of observed regressors, and $\varepsilon_{\mathrm{i}}$ is a vector of unobserved error terms. Here we let the regressor $X_{\mathrm{i}}$ be endogenous in the sense that it depends on $v_{\mathrm{i}}$. In particular, the dichotomous variable $X$ is a function of $R, v$, $W, \eta$, and we express this by writing $X(R, v, W, \eta)$. In the case that $X$ is an indicator of an intervention (here telephone) this specifies the treatment assignment mechanism (Newey and Powell, 2003).
} 
Table 4

Two-stage probit models of voter turnout on mode of contact (2009).

\begin{tabular}{llc}
\hline Variables & Model 1 & \multicolumn{1}{c}{ Model 2 } \\
\hline Telephone contact & $0.013(0.07)$ & $0.038(0.07)$ \\
Combi (mail*tel) & $0.004(0.04)$ & $0.005(0.04)$ \\
Mail contact & $0.037^{*}(0.02)$ & $0.046^{*}(0.02)$ \\
Telephone accessible & $0.196^{*}(0.02)$ & $0.134^{*}(0.02)$ \\
Age (base = 26-45) & & \\
Young 18-25 & - & $-0.487^{*}(0.07)$ \\
Middle/older 45-65 & - & $0.231^{*}(0.03)$ \\
Old age & - & $0.433^{*}(0.04)$ \\
Unknown age & - & $0.326^{*}(0.11)$ \\
Council tax band (base $=D)$ & & \\
Council tax A-C & - & $-0.137^{*}(0.03)$ \\
Council tax E-H & - & $0.116^{*}(0.03)$ \\
Unknown council tax & - & $-0.052(0.04)$ \\
\% Non-white & - & $0.005^{*}(0.00)$ \\
\% Degree & - & $0.008^{*}(0.00)$ \\
\% Owner occupation & - & $0.001(0.00)$ \\
\% Old age & - & $0.014^{*}(0.00)$ \\
\% Long term unemployment & - & $-0.155^{*}(0.05)$ \\
Constant & $-0.454^{*}(0.02)$ & $-0.574^{*}(0.04)$ \\
Wald test exogeneity Chi & $\mathbf{4 3 . 4 7 ^ { * }}$ \\
Log pseudolikelihood & $\mathbf{4 6 . 0 4 *}$ & $-\mathbf{1 4 , 4 6 8 . 4 2}$ \\
$\boldsymbol{N}$ & $-\mathbf{1 5 , 8 0 9 . 3 6}$ & $\mathbf{2 0 , 8 8 8}$ \\
\hline
\end{tabular}

* = Significant at 5\% level; one tailed tests. All models show robust standard errors clustered by 81 wards. All census variables are mean centred. Postal voters are excluded (missing).

All models: Instrumental variable $=$ telephone treatment, mail treatment; Endogenous predictor $=$ telephone contact, mail contact.

Note: Mail treatment is the same as mail contact as contact status is unknown.

telephone treatment assignment is the instrumental variable. Because it is unknown whether direct mail is actually read, in the two-stage model mail treatment and mail contact are equivalent, thus giving the most conservative estimate of the treatment effect (Gerber and Green, 2000a). We pool our sample in a single model, so that the main mail and telephone effects are estimates based on everyone receiving those treatments regardless of whether they belonged to the combination treatment group or the single treatment group. The advantage of this specification is not only that can we observe the effect of mail and telephone across the entire sample, but the effect of synergy is now directly measurable through an interaction parameter between telephone and mail.

Table 4 (model 1) tells us that in 2009 across the whole sample (including those receiving both mail and telephone) the effect of mail is statistically significant and positive. In the descriptive analysis (Table 3 ) this only reached ten per cent significance; but by pooling our treatment groups we have increased the statistical power. The estimated magnitude of the treatment effect, however, is similar to that in Table 3. The predicted turnout rate from the model (for the telephone accessible group) is $41.3 \%$ for those receiving mail compared to $39.8 \%$ for the control group, suggesting a mail treatment effect of 1.4 for telephone accessible (Table 5). ${ }^{11}$ As we would expect, this is

\footnotetext{
11 The predicted values can be calculated with and without the addition of the estimate for telephone accessibility $(+0.196)$ and because it is a non-linear model, the resultant treatment effect varies slightly when this constant is added. In this case, the estimated treatment effect for 'unknowns' is 1.3 rather than 1.4 .
}

close to the estimate shown in Table 3 for the mail treatment group (1.6).

Although the 2009 telephone effect is positive it is not statistically significant. Moreover, receipt of telephone in addition to mail has no significant additional interactive effect suggesting no evidence of synergy. However, it should be noted that the model does not imply that combining mail and telephone is ineffective. Rather, and consistent with the finding in Table 3 above, we see an estimated total (combined) treatment effect of $2.1 \%$ before covariates are added (see Table 5). This implies that the effects of telephone and mail are additive. The model also confirms the importance of telephone accessibility: those with available telephone numbers are simply more likely to vote whether treated or not.

When we introduce a series of individual and neighbourhood (ward) level covariates that are normally correlated with voting (including age of the elector, value of the property at which the subject is resident, and the socioeconomic profile of the area) we find that the results are substantively unaffected (model 2): direct mail did make a difference to turnout with an estimated treatment effect of 1.71 and the mail/telephone combined effect is slightly greater than in the base model at 3.3 (Table 5).

Table 6 shows the equivalent model for 2010 where the mail and telephone treatment refer to all those receiving mail or telephone contact in 2010, regardless of whether they were previously contacted in 2009. Telephone contact is modelled as contact in 2010 and does not represent contact or non-contact in 2009. Any difference that arises from previous contact is captured in this model by the prior vote 2009 variable (in models 2 and 3) which controls for the effect of 2009 vote on 2010 vote. ${ }^{12}$ The interaction term, as before, measures the additional effect of receiving both mail and telephone interventions. Before adding covariates (Table 6, model 1) we find confirmation for the bivariate results presented above: telephone had a significant impact on turnout in 2010, with a model based treatment effect of 4.8 (Table 7). Mail has a smaller but statistically significant effect, with a model based treatment effect of 1.8. There is no significant interaction effect, though the sign is negative. The resultant combined effect estimated from the model is 4.8 , the same as telephone on its own. When covariates are added (models 2 and 3 ) there is a substantial effect of previous vote, but the treatment effects are largely unchanged. The model predicted treatment effect for mail recipients who previously voted is, again, 1.8 and for telephone 4.2. The combined effect (5.1) is now slightly larger than the telephone effect alone, but the interaction is still insignificant and negative. ${ }^{13}$ In short we see evidence of significant mail and telephone effects but no evidence for synergy.

\footnotetext{
12 Pooling the follow up mail/telephone and those receiving mail and telephone combination for the first time, allows us to adjust for contact and estimate the interaction effect between mail and telephone. It does not differentiate between those receiving mail and telephone for the first or second time.

13 When calculated for prior non-voters the model predicted treatment effects were telephone $5.8 \%$, mail $2.1 \%$ and combined $6.2 \%$.
} 
Table 5

Model predicted turnout rates and estimated treatment effects (2009)

\begin{tabular}{lllll}
\hline Treatment & Base model (1) & & Full model (2) \\
\cline { 2 - 4 } & $\begin{array}{l}\text { Predicted turnout \% } \\
\text { (treatment group) }^{\mathrm{a}}\end{array}$ & $\begin{array}{l}\text { Estimated } \\
\text { treatment } \\
\text { effect \% }\end{array}$ & $\begin{array}{l}\text { Predicted turnout \% } \\
\text { treatment group) }^{\mathrm{a}}\end{array}$ & $\begin{array}{l}\text { Estimated } \\
\text { treatment } \\
\text { effect \% }\end{array}$ \\
\hline Mail & 41.3 & 1.4 & 35.6 & 1.7 \\
Telephone & 40.3 & 0.5 & 34.3 & 1.4 \\
Mail + telephone & 41.9 & 2.1 & 36.2 & 3.3 \\
\hline
\end{tabular}

a All predicted values based on telephone accessible, reference category, and mean value on continuous variables. Mail is based on Table 5 model 2 .

\section{Discussion}

Our results indicate that in isolation, the telephone campaign had no significant effect on turnout in the second-order election in 2009, although the effect was in the direction expected. However, the telephone intervention did have a strong significant effect in 2010, increasing turnout by as much as four percentage points (a result that is consistent with John and Brannan (2008)). Moreover, we also showed that this enhanced effect in 2010 was still apparent after controlling for vote in 2009, suggesting that it cannot be attributed to the lingering effect of the 2009

Table 6

Two-stage probit models of voter turnout on mode of contact (2010).

\begin{tabular}{|c|c|c|c|}
\hline Variables & Model 1 & Model 2 & Model 3 \\
\hline Telephone contact & $\begin{array}{l}0.140^{*} \\
(0.04)\end{array}$ & $\begin{array}{l}0.157^{*} \\
(0.05)\end{array}$ & $0.157^{*}(0.05)$ \\
\hline Overall combi (mail*tel) & $\begin{array}{l}-0.050 \\
(0.04)\end{array}$ & $\begin{array}{l}-0.048 \\
(0.04)\end{array}$ & $-0.047(0.04)$ \\
\hline Mail contact & $\begin{array}{l}0.051^{*} \\
(0.02)\end{array}$ & $\begin{array}{l}0.056^{*} \\
(0.03)\end{array}$ & $0.057^{*}(0.03)$ \\
\hline Telephone accessible & $\begin{array}{l}0.114^{*} \\
(0.03)\end{array}$ & $0.045(0.03)$ & $0.039(0.02)$ \\
\hline $\begin{array}{l}\text { Vote } 2009 \text { (includes } \\
\text { postal) }\end{array}$ & - & $\begin{array}{l}1.125^{*} \\
(0.02)\end{array}$ & $1.094^{*}(0.05)$ \\
\hline \multicolumn{4}{|l|}{ Age $($ base $=26-45)$} \\
\hline Young $18-25$ & - & - & $-0.358^{*}(0.08)$ \\
\hline Middle/older 45-65 & - & - & $0.064^{*}(0.03)$ \\
\hline Old age & - & - & $-0.054(0.03)$ \\
\hline Unknown age & - & - & $-0.039(0.14)$ \\
\hline \multicolumn{4}{|l|}{$\begin{array}{l}\text { Council tax band } \\
\quad(\text { base }=D)\end{array}$} \\
\hline Council tax A-C & - & - & $-0.082^{*}(0.03)$ \\
\hline Council tax E-H & - & - & $0.126^{*}(0.05)$ \\
\hline Unknown council tax & - & - & $-0.077(0.05)$ \\
\hline \% Non-white & - & - & $0.004 *(0.00)$ \\
\hline \% Degree & - & - & $0.004(0.00)$ \\
\hline \% Owner occupation & - & - & $0.006 *(0.00)$ \\
\hline$\%$ Old age & - & - & $0.005(0.00)$ \\
\hline $\begin{array}{l}\text { \% Long term } \\
\text { unemployment }\end{array}$ & - & - & $-0.011(0.05)$ \\
\hline Constant & $\begin{array}{l}0.375^{*} \\
(0.03)\end{array}$ & $0.047(0.03)$ & $-0.483^{*}(0.17)$ \\
\hline $\begin{array}{l}\text { Wald test } \\
\text { exogeneity } \mathrm{Chi}^{2}\end{array}$ & $30.67^{*}$ & 13.19* & 14.79* \\
\hline Log pseudolikelihood & $-11,900.78$ & $-10,555.84$ & $-10,419.92$ \\
\hline$N$ & 17,478 & 17,444 & 17,444 \\
\hline
\end{tabular}

* = Significant at $5 \%$ level; one tailed tests. All models show robust standard errors clustered by 81 wards. All census variables are mean centred. Postal voters are excluded (missing).

All models: Instrumental variable = telephone treatment, mail treatment; Endogenous predictor $=$ telephone contact (includes combi contact), mail contact.

Note: Mail treatment is the same as mail contact as we expect $100 \%$ of those who were assigned to the treatment group to be contacted. intervention or of habit formation. Direct mail did have a small but significant impact on voting in 2009 , increasing turnout by a little over $1 \%$ rising to just below $2 \%$ in 2010 .

These results both confirm existing wisdoms, but contain some specific variations that reflect the study design and the context. The most obvious of these is the difference between the two results in 2009 and 2010, which may be down to two factors. First, heterogeneity across elections may result from the variation in salience of the election. The 2010 election was a first order election with a high level of salience, and the resultant level of turnout was much higher than in 2009 by a factor of two. Whilst there is reason to suppose there may be a curvilinear relationship between salience and the efficacy to GOTV treatments (Arceneaux and Nickerson, 2009) the low level of interest in 2009 and the disillusionment with party politics prevalent at the time ${ }^{14}$ appears to have limited the effectiveness of the 2009 treatment relative to 2010 . Second, those receiving telephone or mail treatments in 2010 had also received the equivalent treatment in 2009 which may have led to a reinforcement of the message. This might explain why the effect of telephone increased more than that of mail. Because direct mail is more impersonal than the telephone and the likelihood of recollection (of the previous intervention) is lower, and hence the scope for reinforcement is much less. This was confirmed by evidence from qualitative interviews with a small sample of the treatment groups, which showed very low levels of recollection amongst those who received mail. ${ }^{15}$

While both these explanations my contribute to differences in our results, our study is uniquely suited to identifying election specific effects because we sampled the same geographical locations using the exact same study design in two successive elections. Among the two directly comparable treatment groups - the 2009 combined treatment group and the 2010 'fresh' combined treatment ${ }^{16}$ the 2010 intervention produced a treatment effect

\footnotetext{
${ }^{14}$ The 2009 Elections took place in the middle of a major scandal about MPs expenses in which a number of MPs were forced to repay monies and some were prosecuted. The telephone call team reported a large number of negative reactions from electors alluding to the scandal.

${ }^{15}$ We carried out a number of focus groups in July 2010 in one of our sampled wards for those who had been assigned to the three treatment groups. The aim was to obtain general feedback on the election and to determine whether individuals remembered the intervention (being phoned, mailed or both) and what they thought of it (was it effective or ineffective and if so why).

${ }^{16}$ These are directly comparable because both groups were treated for the first time with identical treatments but at different elections.
} 
Table 7

Model predicted turnout rates and estimated treatment effects (2010).

\begin{tabular}{|c|c|c|c|c|}
\hline \multirow[t]{2}{*}{ Treatment } & \multicolumn{2}{|l|}{ Base model (1) } & \multicolumn{2}{|l|}{ Full model (3) } \\
\hline & $\begin{array}{l}\text { Predicted turnout \% } \\
\text { (treatment group) }^{\mathrm{a}}\end{array}$ & $\begin{array}{l}\text { Estimated } \\
\text { treatment } \\
\text { effect \% }\end{array}$ & $\begin{array}{l}\text { Predicted turnout \% } \\
\text { (treatment group) }^{\mathrm{a}}\end{array}$ & $\begin{array}{l}\text { Estimated } \\
\text { treatment } \\
\text { effect \% }\end{array}$ \\
\hline Mail & 70.5 & 1.8 & 76.0 & 1.8 \\
\hline Telephone & 73.5 & 4.8 & 79.0 & 4.2 \\
\hline Mail \& tel. & 73.5 & 4.8 & 79.3 & 5.1 \\
\hline
\end{tabular}

a All predicted values based on telephone accessible, reference category, and mean value on continuous variables. Full model results based on voters in 2009 (prior vote $=1$ ).

approximately double that of 2009 (4.0 and 2.15 respectively). Moreover, as noted above, the fact that electors receiving the double treatment for the first time were more likely to vote than those receiving the repeat combined treatment would seem to suggest that it was the context of the election rather than the repeat nature of the treatment that is important.

Our analysis also provided important evidence about the synergy of the two modes of intervention. We found that in combination, the treatment was more effective in persuading electors to vote at both elections than either method alone. This was supported by the qualitative interviews which showed that those receiving both forms of contact were much more likely to recollect the content of the message. However, the size of the combined treatment effect suggests nothing more than a simple additive impact (see also Ramirez, 2005; Green, 2004). In other words the total combined treatment effect is not significantly different to the sum of the single telephone treatment effect and the mail treatment effects.

It is also important to note that the there is a substantial difference in the level of turnout between electors who are telephone accessible and those who are not. It suggests a need to be cautious about comparing telephone treatment groups with control groups unless they are pre-screened for telephone accessibility. Failure to do so could lead to overestimation of telephone treatment effects due to the higher prevailing rate of turnout amongst those with accessible telephone numbers. However, there was less evidence that there was any difference in the effectiveness of the treatment across these two groups. ${ }^{17}$ In other words those with and without telephone accessible contact information responded very similarly to the mail intervention.

\section{Conclusions}

This paper analyses a unique nationally representative Get-Out-the-Vote field experiment. Specifically we tested whether impersonal mobilisation methods - both telephone and direct mail - have the potential to increase electoral turnout in the context of a first order and a second order election in England. Using model-based estimation we found that, on the whole, direct mail had significant but limited effectiveness with treatment effects in the range of

\footnotetext{
17 As well as comparing the size of effects across groups in Table 3 above, we tested the interaction between telephone accessibility and the treatments and found no significant effects.
}

1-2 per cent depending on the electoral context. The effectiveness of the telephone treatment was more variable across elections, proving to be considerably more effective in the first order General Election of 2010 than in the second order election of 2009. The second-order European elections have a low level of salience, receiving much less attention that a General Election and the treatments we applied may have been insufficient to push sufficient voters over the necessary threshold of propensity to vote. Moreover the 2009 European Elections were set in the context of a major scandal about financial impropriety amongst MPs, making the electorate even less amenable to persuasion. By contrast, in 2010 the prevailing level of turnout was almost double that in 2009 and the election was closely fought. It seems in this context of heightened awareness the telephone and mail interventions were more likely to succeed.

As well as establishing the effectiveness of telephone and mail GOTV interventions, we have provided rigorous evidence that combining different methods of mobilisation has additive but not interactive effects (Green, 2004; Cardy, 2005; Ramirez, 2005). However, rather than ponder lack of synergy (positive interactive effects) we believe the lack of negative interactions is both important and encouraging to campaigners. Impersonal methods are effective and incremental, accumulating both within and across elections as voters are exposed to multiple contacts. Given that diminishing marginal returns might be a reasonable expectation for GOTV campaigners contacting and re-contacting the same electors, this is perhaps a welcome re-assurance to political parties and campaigners. Although the messages from this research are complex, one thing is quite clear, and that is in the right circumstances both telephone and mail campaigns have an important part to play in mobilizing voters.

\section{References}

Angrist, J.D., Imbens, G.W., Rubin, D.B., Jun., 1996. Identification of causal effects using instrumental variables. Journal of the American Statistical Association 91 (434), 444-455.

Arceneaux, K., 2005. Using cluster randomized field experiments to study voting behavior. The Annals of the American Academy of Political and Social Science 601 (1), 169-179.

Arceneaux, K., Nickerson, 2009. Who is mobilized to vote? A re-analysis of eleven randomized field experiments. American Journal of Political Science 53 (1), 1-16.

Bennion, E., 2005. Caught in the ground wars: mobilizing voters during a competitive congressional campaign. The Annals of the American Academy of Political and Social Science 601 (1), 123-141.

Cardy, E.A., 2005. An experimental field study of the GOTV and persuasion effects of partisan direct mail and phone calls. The Annals of the American Academy of Political and Social Science 601 (1), 28-40. 
Cutts, D., Fieldhouse, E. John, P., 2009. Is voting habit forming? The longitudinal impact of a GOTV campaign in the UK. Journal of Elections, Public Opinion and Parties 19 (3), 251-263.

Fisher, S., Denver, D., 2008. From foot-slogging to call centres and direct mail: a framework for analysing the development of district-level campaigning. European Journal of Political Research 47, 794-826.

Gerber, A., Green, D., 2000a. The effects of canvassing, direct mail, and telephone contact on voter turnout: a field experiment. American Political Science Review 94 (3), 653-663.

Gerber, A., Green, D., 2000b. The effect of a nonpartisan Get-Out-the-Vote drive: an experimental study of leafleting. Journal of Politics 62 (3), 846-857.

Gerber, A., Green, D., 2001. Do phone calls increase voter turnout?: a field experiment. Public Opinion Quarterly 65, 75-85.

Gerber, A., Green, D., 2005. Do phone calls increase voter turnout?: an update. The Annals of the American Academy of Political and Social Science 601 (1), 142-154.

Gerber, A., Green, D., Green, M., 2003. The effects of partisan direct mail on voter turnout. Electoral Studies 22, 563-579.

Goldstein, K.M., Jennings, M.K., 2002. The effect of advance letters on cooperation in a list sample telephone survey. Public Opinion Quarterly 66 (3), 608-617.

Green, D., 2004. Mobilizing African-Americans using direct mail and commercial phone banks: a field experiment. Political Research Quarterly 57 (2), 245-255.

Green, D., Gerber, A., 2004. Get Out the Vote: How to Increase Voter Turnout. Brookings Institution Press, Washington.

Green, D., Gerber, A., Nickerson, D., 2003. Getting out the vote in local elections: results from six door-to-door canvassing experiments. Journal of Politics 65 (4), 1083-1096.

Green, D., Shachar, R., 2000. Habit formation and political behaviour: evidence of consuetude in voter turnout. British Journal of Political Science 30, 561-573.
Green, D., Aronow, P., McGrath, M., 2010. 'Making Sense of 200+ Field Experiments on Voter Mobilization, Part I: Direct Mail', Unpublished Paper, Yale University, August 20.

John, P., Brannan, T., 2008. How different are telephoning and canvassing? Results from a 'Get Out the Vote' field experiment in the UK 2005 General Election. British Journal of Political Science 38, 565-574.

McNulty, J., 2005. Phone-based GOTV-what's on the line? Field experiments with varied partisan components, 2002-2003. The Annals of the American Academy of Political and Social Science 601 (1), 41-65.

Mutz, D.C., 2011. Population-based Survey Experiments. Princeton University Press, Princeton, NJ.

Newey, W.K., Powell, J., 2003. Instrumental variables estimation of nonparametric models. Econometrica 71.

Nickerson, D., 2006. Volunteer phone calls can increase turnout: evidence from eight field experiments. American Politics Research 34 (3), 271-292.

Nickerson, D.W., 2007a. Does email boost turnout? Quarterly Journal of Political Science 2 (4), 369-379.

Nickerson, D.W., 2007b. Quality is job one: professional and volunteer voter mobilization calls. American Journal of Political Science 51 (2), 269-282.

Ramirez, R., 2005. Giving voice to Latino voters: a field experiment on the effectiveness of a national nonpartisan mobilization effort. The Annals of the American Academy of Political and Social Science 601, 66-84.

Rosenstone, S., Hansen, J., 1993. Mobilisation, Participation and Democracy in America. Macmillan, New York.

Trivedi, N., 2005. The effect of identity-based GOTV direct mail appeals on the turnout of Indian Americans. The Annals of the American Academy of Political and Social Science 601 (1), 115-122.

Wong, J., 2005. Mobilizing Asian American voters: a field experiment. The Annals of the American Academy of Political and Social Science 601 (1), 102-114. 